\title{
A Comparison: Accrual Versus Cash Flow Based Financial Measures' Performance in Predicting Business Failure
}

\author{
Shyam Bhandari \\ Bradley University \\ Vince Showers \\ Bradley University
}

Anna J. Johnson-Snyder

East Carolina University

Most business failure prediction models use accrual-accounting-based financial ratios; a few used cash-

flow-based measures. Comparison of the two approaches on the same dataset are rare. This study investigates the prediction accuracy of six accrual-accounting, six cash-flow-based, and the combined 12 ratios on companies' financial data collected during the 2008-2010 recession. Careful to avoid prior research pitfalls (Sharma, 2001), we perform many analyses on a matched set of 50 failed and 50 nonfailing companies. We propose that cash-flow-based measures are better predictors but find that a mixed model of two accrual-accounting-and two cash-flow-based ratios perform significantly better than other models.

Keywords: Business Failure, Discriminant Analysis, Financial Ratios, Cash Flow

\section{INTRODUCTION}

Business failure and the ability to predict it continues to be an ongoing concern of many business' stakeholders for a good reason. Approximately 20 percent of small businesses fail in the first year of operation, and 49 percent fail within the first five-years (Otar, 2018; U.S. Small Business Administration Office of Advocacy, 2018). Preferred CFO reports that small businesses' failure rates are high as a result of poor cash flow management (82\%), improper pricing of products or services $(77 \%)$, and unrealistic sales expectations (73\%) (Flint, 2018, p. 1). Although large and established companies typically have a better survival rate - a company's profitability and ability to survive can quickly change as seen during the 2008 to 2012 great recession. The ability to accurately predict that change depends on the quality of information. The most reliable information available on a company is the audited financial statements.

Data obtained from the three major financial statements are frequently used to calculate financial ratios and construct models to predict bankruptcy, financial distress, or failure. The measures can be divided into two groups: first, ratios calculated using data from the Income Statement (IS) and Balance 
Sheet (BS); second, ratios derived from information on cash flow statement (CFS). Historically, most of the studies rely on accrual-accounting-based ratios using only information from the IS and BS rather than including that on the CFS. This study is motivated by the need for additional research, as suggested in prior literature. For instance, Sharma (2001) claims that research on the "conditions under which cash flow information provides valuable information would be insightful" (p. 22). In 2003, Sharma and Iselin found "strong evidence" that cash flow data, when compared to accrual, improves the predictive value of some credit-related measures (p. 1133). Moreover, traditional measures implemented to assess credit risk or solvency," do not necessarily provide a comprehensive measure of a company's ability" (Dennis, 1994, p. 41).

The number of and use of cash-flow-based ratios in prior studies is a bit one-sided. According to Bellovary, Giacomino and Akers' (2007) Appendix B, prior studies use a total of 562 accrual-accountingbased ratios (hereafter, accrual ratios) versus 92 cash-flow-based ratios (hereafter, CF-based ratios). Hardly any effort has been made to compare the performance of the two approaches on the same data set. The purpose of this paper is to use six financial ratios from each group to see which set performs better in predicting business failure. This paper contributes to the business failure literature in that we find that a combination of two accrual and two CF-based ratios provide better predictive results than either set of six ratios each and the combined 12 -variable based models.

This paper is organized as follows: the next section reviews related literature. It is followed by the methodology section, which explains our null hypothesis, choice of dependent and predictor variables, discriminant analysis technique and sample companies (data). The third section covers the results and analysis. This section includes tables summarizing computer output and discussion of classification results. This is followed by a summary and conclusions. The last section lists the references.

\section{LITERATURE REVIEW}

Over the last fifty years, studies on models to predict business failure, bankruptcies, or distress has proliferated in the USA. Most of the studies use financial ratios, as predictor variables, that are calculated from data available in the two accrual-accounting-based financial statements, i.e., the IS and BS. However, many companies fail from a deficiency in cash flow (Flint, 2018). Prior studies using CFSbased data to build similar prediction models include: Aziz, Emanual and Lawson (1988); Kahya (1997); Gentry, Newbold \& Lawson (1985); Rujoub, Cook \& Hay (1995); Aziz \& Lawson (1989); Bhandari \& Iyer (2013); Cornelius (1985); Gombola, Haskins, Ketz \& Williams (1987); Siegel and Akel (1989); and Sharma (2001). A few noteworthy review articles which also attempted to assess the relative performance of widely cited models are authored by Barnes (1987); Zavgren (1983); Begley, Ming \& Watts (1996); Agarwal \& Taffler (2007); and Sharma (2001). These authors reviewed, evaluated, and compared various studies which attempted construction of bankruptcy prediction models.

Bellovary et al. (2007) paper summarize bankruptcy prediction studies for the 1965-2004 period. The authors review 165 models on bankruptcy prediction and identify specific characteristics across the papers, such as: (1) model sizes drastically vary, e.g., 1 to 57 variables; (2) analyses methods greatly differ, e.g., discriminant, logit, probit, regression analysis; and (3) datasets lack variation, i.e., data from one industry and comprised of bankrupt companies in a specific period. Although very few studies have used bankruptcy or distress prediction models with variables comprised of CFS information, those that have provided evidence that predictors using cash flow from operations has information value. For instance, the argument for using cash flow as predictor variables in constructing models to predict business failure gained momentum in Gentry, Newbold, and Whitford's (1985b) work.

Variables using cash flows from operations (CFO) is supported by two specific studies. The first paper, Gilbert, Menon, and Schwartz (1990), examines the model of CF-based variables by Casey and Bartczak (1985) and that of accrual-based variables by Altman (1968). The authors find that healthy and bankrupt firms are distinguished best by CFO divided by Total Liabilities, which has more information value than suggested by prior literature, e.g., Casey and Bartczak (1985). Moreover, Gilbert et al. find that ratios that best define the performance of a firm are cash flow adequacy, cash flow to sales, and cash flow 
return on assets. Giacomino and Mielke (1993), the second paper, argue that a performance evaluation can be conducted using cash flow ratios by assessing a firm regarding sufficiency and efficiency. When comparing bankruptcy prediction models, the CF-based models are more practical. Cash flow "has significant information content over accrual information in assessing the predicted probability of failure" (Sharma, 2001, p. 4). Interestingly, Sharma (2001) notes that prior studies using CF-based models have mixed or inconclusive results for the following reasons: (1) failed to measure CFO properly; (2) lack of model validation; (3) used old data; (4) ignored some important components of the CFS or variables; and (5) lack the ability to be replicated.

Two studies of interest that compare accrual and CF-based ratios in their ability to provide incremental information as the company's performance measure are by Barac (2010) and Bhandari (2014). In Barac (2010), she defines and calculates 12 accrual and 13 CF-based ratios. Instead of using these ratios as predictor variables to determine their performance, a two-step approach is used. In the first step, a factor analysis is run to extract four latent variables, and, in the second step, a discriminant analysis (DA) is performed to determine the relative importance of the influence of the selected indicators. Further, the author uses Croatian listed companies to test the hypothesis and finds that CFbased ratios have greater incremental information content than the accrual ratios. Bhandari (2014) compares Altman's (1968) paper with Bhandari and Iyer's (2013) paper from a variety of angles. Altman's model is solely based on accrual ratios and only one industry dataset whereas the Bhandari and Iyer's model uses mostly CF-based ratios on multi-industry datasets 45 years later.

In Appendix A of Bellovary et al. (2007), the authors list factors (or ratios) which are used in 165 studies to predict bankruptcy. There is a preponderant use of ratios belonging to the first set: 562 accrualbased ratios versus 92 CF-based ratios. For example, out of the 165 studies, 54 of them use the Net Income to Total Assets (NI/TA) ratio while only 15 use the CFO to Total Assets (CFO/TA). Part of that information, i.e., six accrual and five CF-based ratios, that is relevant to our study is excerpted in Table 1. The number of papers to use a specific ratio is also reported in the table; the difference in usage between the two sets is staggering: 247 studies use the accrual ratios versus only 63 use the CF-based.

To have an equal number of ratio types represented in the analyses, we add the interest coverage of CFO before interest and taxes to the second set. This factor measures a customer's ability to meet minimum loan payments (Dennis, 1994). Thus, we have six predictor variables in each set (accrualversus CF-based ratios) to compare their ability to predict business failure. The accrual ratios or set 1 are: Net Income to Total Assets (NI/TA); Current Ratio (CA/CL); Working Capital to Total Assets (WC/TA); Earnings Before Interest and Taxes to Total Assets (EBIT/TA); Sales to Total Assets (S/TA); and the Quick Ratio, which is the sum of Cash, Non-factored Accounts Receivables, and Prepaid Expenses divided by Current Liabilities. The CF-based ratios in set 2 are: CFO to Total Assets (CFO/TA); CFO to Sales (CFO/S); Cash to Total Assets (C/TA); CFO to Total Liabilities (CFO/TL); CFO to Current Liabilities (CFO/CL); and the sum of CFO, Interest, and Taxes (CFOIT) to Interest (CFOIT/I).

\section{TABLE 1}

FINANCIAL RATIOS USED IN 165 STUDIES TO PREDICT BUSINESS FAILURE*

\begin{tabular}{|l|l|l|l|}
\hline $\begin{array}{l}\text { Accrual-Based Ratios } \\
\text { (Set 1) }\end{array}$ & $\begin{array}{l}\text { Number of Studies to } \\
\text { Include the Specific Ratio }\end{array}$ & $\begin{array}{l}\text { CF-Based Ratios } \\
\text { (Set 2) }\end{array}$ & $\begin{array}{l}\text { Number of Studies to } \\
\text { Include the Specific Ratio }\end{array}$ \\
\hline NI/TA & 54 & CFO/TA & 15 \\
\hline CA/CL & 51 & CFO/S & 9 \\
\hline WC/TA & 45 & C/TA & 18 \\
\hline EBIT/TA & 35 & CFO/TL & 14 \\
\hline S/TA & 32 & CFO/CL & 7 \\
\hline Quick Ratio Total & 30 & CFOIT/I & 0 \\
\hline & 247 & & 63 \\
\hline
\end{tabular}

*Source: Bellovary, Giacomino, and Akers (2007) 


\section{METHODOLOGY}

This paper uses two sets of financial ratios as predictor variables. Set 1 (see Table 1 above) consists of accrual ratios, which uses data from the IS and BS while set 2 contains the CF-based ratios. The dichotomous dependent variables are fail firm (coded "0") and non-fail firm (coded " 1 "). Discriminant analysis is performed on each set of predictor variables to investigate which set or model performs better in predicting business failure. The null hypothesis is:

$\boldsymbol{H}_{\text {0: }}$ Cash-flow-based ratios will not have a higher classification accuracy to predict business failure than the accrual-accounting-based ratios.

Our rationale is that cash is required to make purchases and pay wages, salaries, interest, and current maturity of debt. Real cash is used to compensate stockholders (owners) - not accounting income! "Inadequate cash can lead to a default on accrued payables and ultimate bankruptcy" (Bhandari, 2014, p. 12). The most important and useful information in the BS and CFS is cash. The primary goal of every business is to survive and maintain profitable operations. CFO is that number!

\section{Predictor Variables}

The predictor variables are financial ratios calculated from the information available in three financial statements. There is no limit to the number of ratios that can be calculated from information available on these statements. Many textbook authors limit their coverage to only 15 to 20 similarly defined ratios. Our choice of six accrual-based ratios (set 1) is based on their popularity, simplicity, meaningfulness, and widespread use in addition to their ability to measure liquidity (current ratio and quick ratio), profitability (return on assets and profit margin) and indebtedness (debt ratio and interest coverage). Although CFbased ratios are rarely covered in the finance and accounting textbooks, we chose to use cash or CFO in place of the original numerator in the set 1 ratios to create the set 2 ratios. The resulting six CF-based measures are shown in Table 1 . These ratios are widely referenced and discussed in accounting and finance literature (Refer to Carslaw \& Mills (1991); Figlewics \& Zeller (1991); Fraser \& Ormiston (2010); Mills \& Yamamura (1998); Stickney and Brown (1999); White, Ashwinpaul \& Fried (1997); and Wild, Bernstein \& Subramanyam (2001)).

\section{Models}

Overall, four models are compared and examined for prediction accuracy: (1) accrual ratios or set 1; (2) CF-based ratios or set 2; (3) a 12-variable model that is comprised of set 1 and set 2; and (4) a fourvariable model that contains two accrual- and two CF-based ratios. In the first analyses, set 1 and set 2 are compared and evaluated. In the second analyses, the 12-variable model is evaluated, the results of which are later compared, individually, to those for set 1 and set 2 . In the final analyses, a four-variable model is evaluated, and its results compared to each of the three previous models, i.e., set 1, set 2, and the 12variable model.

\section{Analysis Method}

In this study, a discriminant analysis (DA) is used to process a linear equation comprised of multiple predictor variables $\left(\mathrm{x}_{\mathrm{i}}{ }^{\prime} \mathrm{s}\right)$, e.g., multiple scores, to generate coefficients $\left(\mathrm{a}_{\mathrm{i}}\right.$ 's) to calculate a single weighted-score,"z" that can be used to predict the group membership, i.e., failed versus non-failing, of a company. The linear equation is as follows,

$\mathrm{z}=\mathrm{a}_{0}+\mathrm{a}_{1} \mathrm{x}_{1}+\mathrm{a}_{2} \mathrm{x}_{2}+\ldots \ldots+\mathrm{a}_{\mathrm{n}} \mathrm{x}_{\mathrm{n}}$

which minimizes the discriminant criterion, Wilks' lambda $(\Lambda)$ representing the total variance unexplained, where 
$\Lambda=$ (within-group variance on ' $z$ ' scores) / (total group variance on ' $z$ ' scores).

Under the assumptions of multivariate normality, independence, and homogeneity of the groups' covariance matrices, DA allows for multivariable analysis of variance hypothesis that the two groups (failed companies and non-failing companies) differ significantly on a linear combination of the predictor variables. If found to be significant, the model can be used to allow new cases, i.e., companies, to be classified into one of the two groups, i.e., fail versus non-fail.

DA transforms the original variables into one or more new variables, which are called canonical variables. This process happens in such a way that it will assign the "best" set of weights to each of the predictor variables, i.e., forming the discriminating function, in order to create as much separation as possible between the two levels of the grouping variable. In this study, the group variable is the company status of failed versus non-failing. Given that this study's grouping variable consists of only two groups of companies, the DA procedure will estimate one canonical discriminating function (in general, a maximum of the number of predictor variables or one less than the number of groups, whichever is smallest). From the resulting function, $z$, we can analyze its effectiveness from the eigenvalue ( $\lambda=$ sum of squares between groups/sum of squares within groups), the canonical correlation ( $n=$ square root of [sum of squares between groups/total sum of squares]), the Wilks lambda $(1 /[1+\lambda])$, and the classification matrix (percent of cases correctly classified). In all of these measures except Wilks lambda, the larger the value, the better the estimated function discriminates between the two groups. Also, SPSS uses a transformation of the Wilks lambda to approximate a Chi-square distribution for model significance. These measures are provided in the analysis and used, in part, to identify the "best" model, i.e., from the accrual and CF-based ratios used in this study, to predict the classification of a company as failing (in distress) versus not failing (successful).

\section{DATA}

The great recession of 2008-2012 forced an unusually high number of businesses to declare bankruptcy. Hence, this new dataset of failed (inactive) versus non-failing (active) companies deserves a fresh look to build models which can foresee business failure. A matched sample of 50 failed (hereafter, "fail") and non-failing (hereafter, "non-fail") firms was obtained from the COMPUSTAT database for three years, 2008 through 2010. Firms are matched, first, by the Standard Industrial Classification (SIC) code, and, second, by Total Assets and Sales. Firm's financial data for the year before the inactivity or failure was pulled from the COMPUSTAT database. Each set (set 1 and set 2) of the six ratios were calculated and then subject to discriminant analyses by using the SPSS-22 software.

\section{RESULTS AND ANALYSES}

Results of discriminant analyses (DA) performed on six accrual accounting ratios, six cash-flowbased measures, all the 12 ratios, and 4-variable model (cosisting of two accrual-accounting and two cash-flow-based ratios) are discussed in this section. It also included validation of all these models in many different ways.

\section{Accrual Ratios (Set 1) and CF-based Ratio (Set 2) Analyses}

Table 2 summarizes group means and the univariate test of significance for the 12 predictor variables (six in each set). The values are as expected. For example, both Net Income to Total Assets (NI/TA) and CFO to Total Assets (CFO/TA) are statistically significant and lower in value for fail companies than for non-fail firms $(p<0.050)$. We also find statistically significant differences for many other ratios, namely, the Current Ratio (CA/CL); Quick Ratio; Working Capital to Total Assets (WC/TA); Earnings Before Interest and Taxes to Total Assets (EBIT/TA); CFO to Current Liabilities (CFO/CL); and the CFO to Total Liabilities (CFO/TL); these ratios were lower (and on average, negative) for fail firms. One accrual ratio and three of the CF-based ratios were not significant, which are: Sales to Total Assets (S/TA), CFO 
to Sales $(\mathrm{CFO} / \mathrm{S})$; Cash to Total Assets $(\mathrm{C} / \mathrm{TA})$; and the sum of $\mathrm{CFO}$, Interest, and Tax to Interest (CFOIT/I) ratios. The lack of results for the three CF-based ratios may be attributable to a couple of issues. First, financial data used for the analyses was during the great recession, a period in which many non-fail firms struggled to maintain sales and healthy cash flow. Second, companies that are unable to make a minimum, i.e., interest-only, payment on a loan can be forced into technical bankruptcy by creditors. Therefore, all other methods to obtain cash will be exhausted before a business will fail to make the interest-only payment.

TABLE 2

GROUP MEANS AND UNIVARIATE TEST OF SIGNIFICANCE

\begin{tabular}{|l|r|r|r|r|l|l|r|r|r|}
\hline \multicolumn{4}{|c|}{ Accrual Ratios' Means (Set 1) } & \multicolumn{3}{c|}{ CF-Based Ratios' Means (Set 2) } \\
\hline \multicolumn{1}{|c|}{$\begin{array}{c}\text { Rccrual } \\
\text { Ratios }\end{array}$} & $\begin{array}{c}\text { Fail } \\
\mathrm{n}=43\end{array}$ & $\begin{array}{c}\text { Non- } \\
\text { fail } \\
\mathrm{n}=43\end{array}$ & F-Ratio & Sig. & $\begin{array}{c}\text { CF-based } \\
\text { Ratios }\end{array}$ & $\begin{array}{c}\text { Fail } \\
\mathrm{n}=37\end{array}$ & $\begin{array}{c}\text { Non- } \\
\text { fail } \\
\mathrm{n}=36\end{array}$ & F-Ratio & Sig. \\
\hline CA/CL & 1.097 & 2.269 & 6.859 & 0.010 & CFO/CL & -0.027 & 0.753 & 15.766 & 0.000 \\
NI/TA & -0.636 & 0.033 & 12.089 & 0.001 & CFO/TL & -0.057 & 0.245 & 15.458 & 0.000 \\
Quick Ratio & 0.782 & 1.688 & 4.758 & 0.032 & CFO/TA & -0.115 & 0.105 & 6.273 & 0.015 \\
WC/TA & -0.885 & 0.150 & 5.897 & 0.017 & CFO/S & -0.676 & 0.142 & 1.629 & 0.206 \\
EBIT/TA & -0.379 & 0.083 & 9.053 & 0.003 & C/TA & 0.737 & 0.484 & 2.035 & 0.158 \\
S/TA & 1.124 & 0.878 & 2.752 & 0.101 & CFOIT/INT & -1.950 & 72.434 & 2.623 & 0.110 \\
\hline
\end{tabular}

Table 3 presents the goodness of fit and test of significance measures. The Wilk's Lambda statistics indicate model significance for both the accrual (set 1) and CF-based (set 2) functions. The percent of variance explained by each model is relatively low at 24.9 and 24.0 , respectively.

TABLE 3

\section{GOODNESS OF FIT AND TEST RESULTS FOR THE ACCRUAL AND CF-BASED MODELS}

\begin{tabular}{|l|r|r||l|r|r|}
\hline \multicolumn{1}{|c|}{ Goodness of Fit Measures } & \multicolumn{2}{|c||}{${\text { Function } 1^{\text {a }}}$} & Test Measures & \multicolumn{2}{|c|}{ Function $(\mathrm{df}=6)$} \\
\hline & Accrual & CF-Based & & Accrual & CF-Based \\
\hline Eigenvalue & 0.331 & 0.317 & Wilks' Lambda & 0.751 & 0.760 \\
Canonical Correlation & 0.499 & 0.490 & Chi-square & 23.155 & 18.705 \\
Percentage of Variance Explained & 24.9 & 24.0 & Sig & 0.001 & 0.005 \\
\hline
\end{tabular}

a. The discriminant response variable for both models is binomial and results in only one function. 
TABLE 4

\section{UNSTANDARDIZED DISCRIMINANT FUNCTION COEFFICIENTS} AND GROUP CENTROIDS

\begin{tabular}{|l|r|l|r|}
\hline \multicolumn{2}{|l|}{ Accrual Ratios (Set 1) } & CF-Based Ratios (Set 2) \\
\hline Variable & $\begin{array}{l}\text { Unstandardized } \\
\text { Coefficient }\end{array}$ & Variable & $\begin{array}{l}\text { Unstandardized } \\
\text { Coefficient }\end{array}$ \\
\hline \hline CA/CL & 1.310 & CFO/CL & 0.503 \\
\hline NI/TA & 0.692 & CFO/TL & 1.715 \\
\hline Quick Ratio & -1.248 & CFO/TA & -0.184 \\
\hline WC/TA & -0.114 & CFO/S & -0.404 \\
\hline EBIT/TA & 0.409 & C/TA & 0.0002 \\
\hline S/TA & -0.813 & CFOIT/INT & -0.143 \\
\hline Constant & 0.377 & Constant & -0.547 \\
\hline Group & Centroid & Group & Centroid \\
\hline \hline 0 (Fail) & -0.569 & 0 (Fail) & \multicolumn{2}{|c|}{} \\
\hline 1 (Non-fail) & 0.569 & 1 (Non-fail) & \multicolumn{2}{|c|}{} \\
\hline
\end{tabular}

Table 4 presents the unstandardized discriminant function coefficients and group centroids for each set of predictor variables. A critical or ' $z$ ' value is generated when each ratio is multiplied by the respective coefficient and tallied; the proximity of this ' $z$ ' value to the group centroid can be used to assess the level of financial distress (or success) of a company. However, based on the results, either model can equally predict the financial health of an organization. Hence, further analyses were performed to assess the validation or level of accuracy of each set.

\section{Validation of Accrual and CF-based Models}

Our models have been validated in many different ways. The classification accuracy for both the test models is presented in Table 5. The classification accuracy of CF-based ratios (set 2) of 80.8\% is higher than that of the accrual ratios (set 1) 76.7\%. To check for upward bias in the classification table, crossvalidation was performed using the leave-one-out (or jackknife) approach. Overall, the accuracy (crossvalidated grouped cases correctly classified) is higher for the CF-based set $(80.8 \%)$ while that of the accrual set shows it yielding even lower accuracy (70.9\%).

TABLE 5

\section{CLASSIFICATION RESULTS: ACCRUAL VERSUS CF-BASED MODELS}

\begin{tabular}{|c|c|c|c|c|c|c|c|}
\hline & \multirow[b]{2}{*}{ Group } & \multicolumn{3}{|c|}{$\begin{array}{c}\text { Accrual Ratios (Set 1) } \\
\text { Predicted Group Membership }\end{array}$} & \multicolumn{3}{|c|}{$\begin{array}{c}\text { CF-Based Ratios (Set 2) } \\
\text { Predicted Group Membership }\end{array}$} \\
\hline & & Fail $(0)$ & Non-fail (1) & 86 firms & Fail $(0)$ & Non-fail (1) & 73 firms \\
\hline \multirow[t]{2}{*}{ Observed } & Fail (0) & $\begin{array}{c}29 \\
(67.4 \%) \\
\end{array}$ & $\begin{array}{c}14 \\
(32.6 \%) \\
\end{array}$ & Overall & $\begin{array}{c}32 \\
(86.5 \%)\end{array}$ & $\begin{array}{c}5 \\
(13.5 \%)\end{array}$ & Overall \\
\hline & Non-fail (1) & $\begin{array}{c}6 \\
(14.0 \%) \\
\end{array}$ & $\begin{array}{c}37 \\
(86.0 \%) \\
\end{array}$ & $(76.7 \%)$ & $\begin{array}{c}9 \\
(25.0 \%) \\
\end{array}$ & $\begin{array}{c}27 \\
(75.0 \%) \\
\end{array}$ & $(80.8 \%)$ \\
\hline \multicolumn{4}{|c|}{ Cross-validated grouped cases correctly classified } & $(70.9 \%)$ & \multicolumn{3}{|r|}{$(80.8 \%)$} \\
\hline \multicolumn{4}{|c|}{$\mathrm{B}-$ Index for a measure of prediction accuracy $=$} & 0.8223 & \multicolumn{3}{|r|}{0.8217} \\
\hline \multicolumn{4}{|c|}{$\mathrm{C}-$ Index for a measure of discriminating groups $=$} & $83.8 \%$ & \multicolumn{3}{|r|}{$86.0 \%$} \\
\hline
\end{tabular}

The B-index and C-index were also calculated to examine if one set performs "better" than the other. The B-index is a measure of predictive accuracy, while the $\mathrm{C}$-index, like the simple classification table, 
provides another measure of discriminating ability. If an individual repeatedly and randomly selects two pairs of companies, one fail and one non-fail, the $\mathrm{C}$-index provides the percent of the time that an individual can expect to accurately identify a fail firm over a non-fail firm using the estimated discriminant model. In other words, the C-index provides an accuracy rate for the whichever set, set 1 or set 2 , is being evaluated. The B-index shows very similar measures of accuracy for both the CF-based and the accrual methods ( 0.8223 and 0.8217 , respectively). In contrast, the $\mathrm{C}$-index favors the predictive power of the CF-based variables over the accrual variables, $86.0 \%$ to $83.8 \%$, respectively. The chi-square test results show a significant difference in the two proportions $(p$-value $=0.000)$, indicating the CFbased model yields a significantly higher proportion of concordant cases (i.e., the probability event is predicted to be in group $\mathrm{i}>$ probability event $\mathrm{j}$ is predicted to be in group i).

Non-parametric tests for a difference between proportions were performed on the classification results. The chi-square results show that both sets (1 and 2$)$ do not differ, statistically, in their ability to correctly classify a company as fail versus non-fail ( $p$-value $=0.667)$. Also, when examining only matched observations, the nonparametric McNemar test found no difference in the "disagreements" between the classifications of the two sets $(p$-value $=0.502)$, again suggesting no significant difference in classification accuracy. When the results of the many analyses are reviewed, we find that the CF-based model has information value when compared to the accrual-based model, but the results are mixed on which model is best for overall prediction purposes.

Although most of the studies use accrual-based ratios, a few use a combination of accrual- and CFbased ratios. Thus, considering the mixed results on the individual sets (set 1 and 2), we performed a DA that contains all the 12 predictor variables to test if the larger model has higher classification accuracy. This approach resulted in 71 usable cases. Table 6 summarizes group means and the univariate test of significance for the 12 ratios. All ratios, except CFO to Sales (CFO/S), Cash to Total Assets (C/TA) and the sum of CFO, Interest, and Tax to Interest (CFOIT/I), are significant at 5\% level. Again, the results for the three non-significant variables is not surprising considering the economic conditions in play during the period covered by the dataset used for the analyses.

TABLE 6 GROUP MEANS AND TESTS OF SIGNIFICANCE (12-VARIABLE MODEL)

\begin{tabular}{|l|r|r|r|r|}
\hline & \multicolumn{2}{|c|}{ Group Means } & & \\
\hline & \multicolumn{1}{|c|}{$\begin{array}{c}\text { Fail } \\
\mathrm{n}=35\end{array}$} & \multicolumn{1}{c|}{$\begin{array}{c}\text { Non-fail } \\
\mathrm{n}=36\end{array}$} & \multicolumn{1}{c|}{ F-Ratio } & \multicolumn{1}{c|}{ Sig. } \\
\hline Ratios & -0.034 & 0.776 & 16.301 & 0.000 \\
CF-Based Ratios: & -0.064 & 0.252 & 16.247 & 0.000 \\
CFO/TL & -0.121 & 0.108 & 6.464 & 0.013 \\
CFO/TA & -0.696 & 0.147 & 1.636 & 0.205 \\
CFO/S & 0.651 & 0.496 & 0.950 & 0.333 \\
C/TA & -2.525 & 74.511 & 2.665 & 0.107 \\
CFOIT/INT & & & & \\
& & & & \\
Accrual Ratios: & 0.793 & 1.886 & 21.518 & 0.000 \\
CA/CL & -0.419 & 0.025 & 14.888 & 0.000 \\
NI/TA & 0.486 & 1.270 & 19.189 & 0.000 \\
Quick Ratio & -0.574 & 0.127 & 12.500 & 0.001 \\
WC/TA & -0.224 & 0.099 & 6.736 & 0.012 \\
EBIT/TA & 1.204 & 0.878 & 4.436 & 0.039 \\
S/TA & & & & \\
\hline
\end{tabular}




\section{Validation of 12-variable Model}

Table 7 summarizes the classification results of the DA performed on the 12-variable model. Interestingly, the classification accuracy of the larger model $(80.3 \%)$ is better than that achieved by the accrual ratios or set 1 (76.3\%; presented in Table 5), but it is slightly less than that of the CF-based ratios or set $2(80.8 \%$; presented in Table 5). We find no significant differences in using either the chi-square test or the McNemar test. The unbiased cross-validation classification accuracy for the 12-variable model $(74.6 \%)$ is, again, better than the accuracy of the accrual set $(70.9 \%)$ and worse than that of the CF-based set (80.8\%). Moreover, the B-Index and C-Index are both noticeably higher for the large (12-variable) model (88.53\% and $93.1 \%$, respectively) compared to the accrual and CF-based models. Specifically, the 93.1\% C-index concordance for the 12-ratio model is significantly higher than that of both the accrual $(83.8 \%)$ and CF-based $(86.0 \%)$ models based on the chi-square test ( $p$-values $=0.000)$. While not overwhelming, these results provide some indication that a combination of the accrual and CF-based ratios may provide better predictive power of a company's potential failure.

TABLE 7

CLASSIFICATION RESULTS (12-VARIABLE MODEL)

\begin{tabular}{|l|l|l|l|l|}
\hline \multirow{2}{*}{\multicolumn{2}{|c|}{}} & \multicolumn{3}{|c|}{$\begin{array}{c}\text { Accrual and CF-Based Ratios } \\
\text { Predicted Group Membership }\end{array}$} \\
\cline { 2 - 5 } & Fail (0) & Non-fail (1) & 71 firms \\
\hline \hline \multirow{2}{*}{ Observed } & Fail (0) & $28(77.8 \%)$ & $8(22.2 \%)$ & Overall \\
\cline { 2 - 4 } & Non-fail (1) & $6(17.1 \%)$ & $29(82.9 \%)$ & $\mathbf{( 8 0 . 3 \% )}$ \\
\hline \multicolumn{4}{|c|}{ Cross-validated grouped cases correctly classified = } & $(74.6 \%)$ \\
\hline \multicolumn{4}{|l|}{ B - Index for a measure of prediction accuracy $=$} & 0.8853 \\
\hline C - Index for a measure of discriminating groups $=$ & $93.1 \%$ \\
\hline
\end{tabular}

Table 8 summarizes test results from the 12-variable analysis. The Wilks' lambda is significant ( $p$ value $=0.000$ ). The unstandardized discriminant function coefficient and group centroids are available in Table 9 for readers interested in performing the prediction of success (non-fail) and distress (fail) of any company.

TABLE 8

GOODNESS OF FIT AND TEST RESULTS (12-VARIABLE MODEL)

\begin{tabular}{|r|r||r|r|}
\hline Goodness of Fit Measures & Function $1^{\mathrm{a}}$ & Test Measures & Function (df=12) \\
\hline \hline Eigenvalue & 0.839 & Wilks' Lambda & 0.544 \\
\hline Canonical Correlation & 0.675 & Chi-square & 38.365 \\
\hline Percent of Variance Explained & 45.6 & Sig & 0.000 \\
\hline
\end{tabular}

a. The discriminant response variable for both models is binomial, resulting in only one function. 
TABLE 9

UNSTANDARDIZED DISCRIMINANT FUNCTION COEFFICIENTS AND GROUP CENTROIDS (12-VARIABLE MODEL)

\begin{tabular}{|l|r|}
\hline \multicolumn{2}{|l|}{ Accrual and CF-Based Ratios } \\
\hline Variable & $\begin{array}{l}\text { Unstandardized } \\
\text { Coefficient }\end{array}$ \\
\hline \hline CFO/CL & 0.251 \\
\hline CFO/TL & 3.543 \\
\hline CFO/TA & -5.029 \\
\hline CFO/S & 0.268 \\
\hline C/TA & 0.378 \\
\hline CFOIT/INT & -0.001 \\
\hline CA/CL & 1.081 \\
\hline NI/TA & 1.566 \\
\hline Quick Ratio & -1.404 \\
\hline WC/TA & 0.379 \\
\hline EBIT/TA & 0.558 \\
\hline S/TA & -0.928 \\
\hline (Constant) & 0.617 \\
\hline Group & Centroid \\
\hline \hline 0 (Fail) & -0.890 \\
\hline 1 (Non-fail) & 0.916 \\
\hline
\end{tabular}

Four-variable Model Versus the Other Three (12-variable and Two 6-variable) Models

A 12-variable model is overkill and can hinder the discriminating ability of a DA model. For the sake of parsimony, we examined if a model with smaller set of explanatory variables would do a better job. We found that four variables, the variables most highly correlated with the standardized canonical discriminant function resulted in the highest percentage $(88.4 \%)$ of cases classified correctly, which is far better than the classification accuracy of $80.3 \%, 76.7 \%$ and $80.8 \%$ for 12 -variable model, 6-variable accrual ratio model and CF-based model respectively (see Table 7 and 5). These four variables are: Current Ratio (CA/CL; accrual-based); Net Income to Total Assets (NI/TA; accrual-based); CFO to Current Liabilities (CFO/CL; CFS-based) and CFO to Total Liabilities (CFO/CL; CFS-based). Table 10 summarizes the group means and univariate test of significance for 86 valid cases. All these have F-ratio highly significant at $1 \%$ level.

TABLE 10

GROUP MEANS AND UNIVARIATE TEST OF SIGNIFICANCE (4-VARIABLE MODEL)

\begin{tabular}{|l|r|r|r|r|}
\hline \multicolumn{5}{|c|}{ Accrual and CF-Based Ratios' Means } \\
\hline Ratios & $\begin{array}{c}\text { Fail } \\
\text { N=43 }\end{array}$ & $\begin{array}{c}\text { Non-fail } \\
\text { N=43 }\end{array}$ & F-Ratio & Sig. \\
\hline CFO/CL & -0.2778 & 0.8073 & 19.024 & 0.000 \\
CFO/TL & -0.2344 & 0.3429 & 10.422 & 0.002 \\
\hline CA/CL (accrual) & 1.0970 & 2.2691 & 6.859 & 0.010 \\
NI/TA (accrual) & -0.6357 & 0.0329 & 12.089 & 0.001 \\
\hline
\end{tabular}




\section{Validation of 4-variable Model}

Table 11 presents the classification results when only these four variables are used as explanatory variables. The results are very impressive! For instance, $90.7 \%$ of the fail and $86 \%$ of the non-fail companies are correctly classified. Both the overall and cross-validated classification accuracy rates are the same $(88.4 \%)$. Also, the B-index and C-index for the mixed four-variable model are higher $(0.8405$ and $92.3 \%$, respectively) than those for the 12 -variable, accrual-based, and CF-based models. While the classification accuracy percentages do not differ significantly among the four models, at the 0.05 level, the four-variable mixed model is significantly higher, at the 0.01 level, when compared to the accrualbased (set 1) model. Additional analysis shows that the C-index is significantly higher for the fourvariable mixed model when it is compared to each of the other three models (chi-square p-values $=$ 0.000). Further, when comparing cases paired across models, the McNemar test shows that the fourvariable model performs significantly better, at the 0.05 level, against the accrual-based model ( $p$-value $=$ $0.022)$ and significantly better, at the 0.10 level, against the CF-based model $(p$-value $=0.070)$.

TABLE 11

CLASSIFICATION RESULTS (4-VARIABLE MODEL)

\begin{tabular}{|c|c|c|c|c|}
\hline & \multirow[b]{2}{*}{ Group } & \multicolumn{3}{|c|}{$\begin{array}{l}\text { Accrual (two) and CF-Based (two) Ratios } \\
\text { Predicted Group Membership }\end{array}$} \\
\hline & & Fail $(0)$ & Non-fail (1) & 86 firms \\
\hline \multirow[t]{2}{*}{ Original } & Fail (0) & $39(90.7 \%)$ & $4(8.3 \%)$ & Overall \\
\hline & Non-fail (1) & $6(14.0 \%)$ & $37(86.0 \%)$ & $(88.4 \%)$ \\
\hline \multicolumn{4}{|c|}{ Cross-validated grouped cases correctly classified $=$} & $(88.4 \%)$ \\
\hline \multicolumn{4}{|c|}{$\mathrm{B}-$ Index for a measure of prediction accuracy $=$} & 0.8405 \\
\hline \multicolumn{4}{|c|}{$\mathrm{C}-$ Index for a measure of discriminating groups $=$} & $92.3 \%$ \\
\hline
\end{tabular}

Table 12 is the summary of test results from the DA on the four-variable model. Wilks' lambda is significant $(p=0.000)$. While the percent of variance explained is, not surprisingly, higher for the 12variable model, in terms of predicting fail versus non-fail, the results lead us to conclude that a combination of two accrual and two CF-based ratios (4-variable model) gives better results than the 6variable accrual (set 1) and 6-variable CF-based (set 2) models. Table 13 also has unstandardized discriminant function coefficients and group centroids for facilitating the prediction of success and distress of a new firm.

TABLE 12

GOODNESS OF FIT AND TEST RESULTS (4-VARIABLE MODEL)

\begin{tabular}{|r|r||r|r|}
\hline Goodness of Fit Measures & Function $1^{\mathrm{b}}$ & Test Measures & Function (df=12) \\
\hline \hline Eigenvalue & 0.389 & Wilks' Lambda & 0.720 \\
\hline Canonical Correlation & 0.529 & Chi-square & 26.937 \\
\hline Percent of Variance Explained & 28.0 & Sig & 0.000 \\
\hline
\end{tabular}

b. The discriminant response variable for both models is binomial and results in only one function. 
TABLE 13

\section{UNSTANDARDIZED DISCRIMINANT FUNCTION COEFFICIENTS AND GROUP} CENTROIDS (4-VARIABLE MODEL)

\begin{tabular}{|l|r|}
\hline Variable & $\begin{array}{l}\text { Unstandardized } \\
\text { Coefficient }\end{array}$ \\
\hline CFO/CL & 0.032 \\
\hline $\mathrm{CFO} / \mathrm{TL}$ & 0.196 \\
\hline $\mathrm{CA} / \mathrm{CL}$ & 0.585 \\
\hline $\mathrm{NI} / \mathrm{TA}$ & 0.522 \\
\hline (Constant) & -0.329 \\
\hline Group & Centroid \\
\hline \hline 0 (Fail) & -0.616 \\
\hline 1 (Non-fail) & 0.616 \\
\hline
\end{tabular}

\section{Validation of 4-variable Model Using Split Sample Methodology}

For a small sample cross-validation (also known as a jackknife or leave-one-out) method is considered as an unbiased test of classification accuracy. For a large sample, a hold-out or split-sample approach is highly recommended. We, therefore, divided our 100 firms into two groups: The first group consisting of 70 randomly selected companies for model development and the leftover 30 companies as the second (holdout) group for validation. Because of the better performing parsimonious 4-variable model, we performed a DA on these four variables. The group means and univariate test of significance of valid cases (62 for model development \& 24 for hold-out) for both subsets are summarized in Table 14. The group means for fail and non-fail firms are as expected. For example, CFO/CL and CA-CL ratios are significantly smaller for fail firms than for non-fail firms.

Table 15 summarizes classification results for both groups of companies. In the first model development group, we find that $87.1 \%$ of cases are correctly classified, whereas, in the second hold-out sample, of 24 valid companies, $83.3 \%$ are correctly classified. The strong hold-out sample results, again, suggests solid support for a more parsimonious and mixed-ratios approach for predicting business failure.

\section{On Equality of Covariance Matrix Assumption}

The natural logarithms of determinants of the group covariance matrices and the Box's M tests indicate the population covariance matrices differ between the fail and non-fail groups, with the fail group having the greater variance for all models examined. While DA is robust with a large sample size for the inferential statistics, it is not known to be robust for classification purposes. Because of this, the classification for each of the models examined was also done using separate group covariances (as opposed to using the traditional pooled within-groups covariance matrix). While classification accuracies are approximately 5-6\% lower for the accrual (set 1) and CF-based (set 2) models, the percentage correctly classified for the 12-variable and 4-variable models are nearly identical to the method in which equal variances are assumed. Given these insignificant differences, especially for the more accurate models, and the fact that Box's M can be overly sensitive in large samples, all classifications presented are based on using pooled within-group covariance matrices. Also, the Wilks' lambda, canonical correlation, and the discriminate function coefficients were not affected by the method chosen. 
TABLE 14

GROUP MEANS AND UNIVARIATE TEST OF SIGNIFICANCE FOR MODEL DEVELOPMENT SAMPLE AND HOLD-OUT SAMPLE (4-VARIABLE MODEL)

\begin{tabular}{|c|c|c|c|c|c|}
\hline Sample & Ratios & $\begin{array}{c}\text { Fail } \\
\mathrm{N}=29\end{array}$ & $\begin{array}{c}\text { Non-fail } \\
\mathrm{N}=33\end{array}$ & F-Ratio & Sig. \\
\hline \multirow{5}{*}{$\begin{array}{l}\text { Model Development Sample } \\
\text { (62 cases) }\end{array}$} & $\mathrm{CFO} / \mathrm{CL}$ & -0.4135 & 0.8331 & 14.937 & 0.000 \\
\hline & $\mathrm{CFO} / \mathrm{TL}$ & -0.3343 & 0.3268 & 8.373 & 0.005 \\
\hline & CA/CL (accrual) & 1.2804 & 2.0959 & 2.746 & 0.103 \\
\hline & NI/TA (accrual) & -0.6636 & 0.0380 & 8.257 & 0.006 \\
\hline & & $\mathrm{N}=14$ & $\mathrm{~N}=10$ & & \\
\hline \multirow{4}{*}{$\begin{array}{l}\text { Hold-out Sample } \\
\text { ( } 24 \text { cases) }\end{array}$} & $\mathrm{CFO} / \mathrm{CL}$ & 0.0034 & 0.7221 & 4.847 & 0.047 \\
\hline & $\mathrm{CFO} / \mathrm{TL}$ & -0.0274 & 0.3960 & 2.713 & 0.114 \\
\hline & CA/CL (accrual) & 0.7169 & 2.8408 & 4.446 & 0.047 \\
\hline & NI/TA (accrual) & -0.5779 & 0.0163 & 3.938 & 0.060 \\
\hline
\end{tabular}

TABLE 15

CLASSIFICATION RESULTS FOR THE 4-VARIABLE MODEL (HOLD-OUT SAMPLE APPROACH)

\begin{tabular}{|c|c|c|c|c|c|c|}
\hline \multirow[b]{2}{*}{ Group } & \multicolumn{3}{|c|}{$\begin{array}{c}\text { Model Development Sample (62) } \\
\text { Predicted Group Membership }\end{array}$} & \multicolumn{3}{|c|}{$\begin{array}{l}\text { Hold-out sample (24) } \\
\text { Predicted Group Membership }\end{array}$} \\
\hline & Fail (0) & Non-fail (1) & 62 firms & Fail (0) & Non-fail (1) & 24 firms \\
\hline Fail (0) & $\begin{array}{c}25 \\
(86.2 \%)\end{array}$ & $\begin{array}{c}4 \\
(13.8 \%) \\
\end{array}$ & Overall & $\begin{array}{c}12 \\
(85.7 \%)\end{array}$ & $\begin{array}{c}2 \\
(14,3 \%)\end{array}$ & Overall \\
\hline Non-fail (1) & $\begin{array}{c}4 \\
(12.1 \%)\end{array}$ & $\begin{array}{c}29 \\
(87.9 \%)\end{array}$ & $(87.1 \%)$ & $\begin{array}{c}2 \\
(20.0 \%)\end{array}$ & $\begin{array}{c}8 \\
(80.0 \%)\end{array}$ & $(83.3 \%)$ \\
\hline \multicolumn{3}{|c|}{ Cross-validated grouped cases correctly classified } & $(87.1 \%)$ & - & - & - \\
\hline \multicolumn{3}{|c|}{$\mathrm{B}-$ Index for a measure of prediction accuracy $=$} & 0.8440 & - & - & 0.8421 \\
\hline \multicolumn{3}{|c|}{$\mathrm{C}-$ Index for a measure of discriminating groups $=$} & $91.6 \%$ & - & - & $95.5 \%$ \\
\hline
\end{tabular}

\section{SUMMARY AND CONCLUSION}

Most of the models constructed to predict business failure use accrual-accounting-based financial ratios; a few use cash-flow-based measures. However, hardly any study compares the two approaches on the same dataset. This paper attempts to do that. Two sets of financial ratio measures, i.e., accrualaccounting-based (set 1) and CF-based (set 2), are used to compare the performance in predicting business failure. Although the CF-based set of ratios (set 2) performed better than the set of accrual-based ratios (set 1). in terms of percentage classification accuracy and B-Index, the results were not statistically significant. These results suggest that accrual ratios are as good a predictor of corporate failure as the CFbased ratios. Therefore, we can infer that the so-called "quality of earning" is reflected in the net income reported during the 2008-2012 recession period.

Our inconclusive results prompted us to use the 12 ratios (accrual- and CFS-based ratios), referred to as the 12-variable model, to explore the possibility that a discriminant analysis model based on these twelve measures will perform better than either of the two ratio models (set 1 and set 2). Again, the results are mixed. The 12-variable model performs marginally better than the accrual set but worse than 
the CF-based set. However, the B-Index and C-Index measures of prediction accuracy for the 12-variable model are significantly higher than that for either of the six-ratio models.

For the sake of simplicity and parsimony, we extracted four top-loading variables (Current Ratio, Net Income to Total Assets, CFO to Current Liabilities, and CFO to Total Liabilities) and performed discriminant analyses on the whole data set as well as on the split samples. The results are very impressive. The four-variable model (two accrual-based and two CFS-based ratios) outperforms all other models, not only regarding classification accuracy on the original dataset but also on the holdout sample. It also has a higher classification accuracy using the leave-one-out or jackknife cross-validation and the non-parametric B-Index and C-Index measures.

We proposed that CF-based measures are a better predictor of a firm's survival than the accrualaccounting-based measures. The results are mixed. However, a mixture of two accrual-accounting- and two CF-based ratios perform significantly better. Further study is needed to support or refute our argument. This might include a different or expanded set of financial ratio measures, a larger sample of firms and/or different multivariate statistical techniques.

\section{REFERENCES}

Agarwal, V., \& Taffler, R. (2007). Twenty-five years of the Taffler z-score model: Does it really have predictive ability? Accounting and Business Research, 37(4), 285-300.

Altman, E. I. (1968). Financial ratios, discriminant analysis and the prediction of corporate bankruptcy. Journal of Finance, 23(4), 589-609.

Aziz, A., Emanuel, D. C., \& Lawson, G. H. (1988). Bankruptcy prediction - An investigation of cash flow based models. Journal of Management Studies, 25(5), 419-437.

Aziz, A., \& Lawson, G. H. (1989). Cash flow reporting and financial distress models: Testing of hypotheses. Financial Management, 18(1), 55-63.

Barac, Z. A. (2010). Cash Flow Ratios vs. Accrual Ratios: Empirical Research on Incremental Information Content. The Business Review, Cambridge, 15(2), 206-213.

Barnes, P. (1987). The analysis and use of financial ratios: A review article. Journal of Business Finance \& Accounting, 14(4), 449-461.

Begley, J., Ming, J., \& Watts, S. (1996). Bankruptcy classification errors in the 1980's: An empirical analysis of Altman's and Olson's Models. Review of Accounting Studies, 1(4), 267-284.

Bellovary, J. L., Giacomino, D. E., \& Akers, M. (2007). A review of bankruptcy prediction studies: 1930 to present. Journal of Financial Education, 33(1), 1-42.

Bhandari, S. B. (2014). Two discriminant analysis models of predicting business failure: A contrast of the most recent with the first model. American Journal of Management, 14(3), 11-19.

Bhandari, S. B., \& Iyer, R. (2013). Predicting business failure using cash flow statement based measures. Managerial Finance, 39(7), 667-676.

Carslaw, C. A., \& Mills, J. R. (1991). Developing ratios for effective cash flow statement analysis. Journal of Accountancy, 172(5), 63-69.

Casey, C., \& Bartczak, N. (1985). Using operating cash flow data to predict financial distress: Some extensions. Journal of Accounting Research, 23(1), 384-401.

Cornelius, G. W. (1985). Evaluation fairness and work motivation. University of Illinois, Champaign.

Dennis, M. C. (1994). Understanding cash flow statements. Business Credit, 96(1), 41-42.

Figlewics, R. E., \& Zeller, T. L. (1991). An analysis of performance, liquidity, coverage, and capital ratios from the Statement of Cash Flows. Akron Business and Economic Review, 22(1), 64-81.

Flint, M. (2018, March 8). Cash flow: The reason 82 percent of small businesses fail. Preferred CFO (Online), pp. 1-5. Retrieved from https://www.preferredcfo.com/cash-flow-reason-smallbusinesses-fail/

Fraser, L., \& Ormiston, A. M. (2010). Understanding Financial Statements (9th ed.). Upper Saddle River, NJ: Pearson Prentice Hall.

24 Journal of Accounting and Finance Vol. 19(6 2019 
Gentry, J. A., Newbold, P., \& Whitford, D. T. (1985a). Classifying bankrupt firms with funds flow components. Journal of Accounting Research, 23(1), 146-160.

Gentry, J. A., Newbold, P., \& Whitford, D. T. (1985b). Predicting bankruptcy: If cash flow's not the bottom line, what is? Financial Analysts Journal, 41(5), 47-56.

Giacomino, D. E., \& Mielke, D. E. (1993). Cash flows: Another approach to ratio analysis. Journal of Accountancy, 175(3), 55-60.

Gilbert, L. R., Menon, K., \& Schwarts, K. B. (1990). Predicting bankruptcy for firms in financial distress. Journal of Business Finance, 17(1), 161-171.

Gombola, M. J., Haskins, M. E., Ketz, J. E., \& Williams, D. D. (1987). Cash flow in bankruptcy predictions. Financial Management, 16(4), 55-65.

Kahya, E. (1997). Prediction of business failure: A fund flow approach. Managerial Finance, 23(3), 6471.

Mills, J. R., \& Yamamura, J. H. (1998). The power of cash flow ratios. Journal of Accountancy, 186(4), $53-61$.

Otar, C. (2018, October 25). What percentage of small businesses fail-- And how can you avoid being one of the them? Forbes (Online), pp. 1-4. Retrieved from https://www.forbes.com/sites/forbesfinancecouncil/2018/10/25/what-percentage-of-smallbusinesses-fail-and-how-can-you-avoid-being-one-of-them/\#35058f0543b5

Rujoub, M. A., Cook, D. M., \& Hay, L. E. (1995). Using cash flow ratios to predict business failures. Journal of Managerial Issues, 7(1), 75-90.

Sharma, D. S. (2001). The role of cash flow information in predicting corporate failure: The state of the literature. Managerial Finance, 27(4), 3-28.

Sharma, D. S., \& Iselin, E. R. (2003). The relative relevance of cash flow and accrual information for solvency assessments: A multi-method approach. Journal of Business Finance and Accounting, 30(7/8), 1115-1140

Sharma, S. (1996). Applied Multivariate Techniques. New York, NY: John Wiley \& Sons, Inc.

Siegel, J. G., \& Akel, A. (1989). A financial analysis and evaluation of the Statement of Cash Flows. The Practical Accountant, 22, 71-78.

Stickney, C. P., \& Brown, P. R. (1999). Financial Reporting and Statement Analysis: A Strategic Perspective (4th ed.). Fort Worth, TX: The Dryden Press.

U.S. Small Business Administration Office of Advocacy. (2018). Frequently Asked Questions About Small Business, 2018. Retrieved from www.sba.gov/advocacy/veteran-owned-businesses-andtheir-owners.

White, G. I., Ashwinpaul, C., \& Fried, D. (1997). The Analysis and Use of Financial Statements (2nd ed.). New York, NY: John Wiley \& Sons, Inc.

Wild, J. J., Bernstein, L. A., \& Subramanyam, K. R. (2001). Financial Statement Analysis. New York, NY: McGraw-Hill Higher Education

Zavgren, C. V. (1983). The prediction of corporate failure: The state of the art. Journal of Accounting Literature, 2, 1-3 